\title{
Analysis of Output Characteristics of Buck Converter
}

\author{
Jinquan Wang, Qian Li, Pengchao Song, Pengfei Hou \\ Engineering Institute of Defence, PLA University of Science\&Technology, Nanjing, China \\ Email: lqtx_0@qq.com \\ Received February, 2013
}

\begin{abstract}
This Article introduced the concept, topology and function of voltage type Buck converter, built a small signal model, analysis the negative impedance character of converter, then simulated a Buck-type DC/ DC through MATLAB, observed the dynamic response of converter to pulse-type power load, verified the small-signal theoretical by simulation, lay the foundation for analyzing DC system stability.
\end{abstract}

Keywords: Small-signal Model; Nput Impedance; Buck Converter; DC System

\section{Introduction}

With the rapid development of power electronics technology and electricity, the number of electronic devices has more and more extensive application in the grid. Such a wide range of applications also causing a series of bad effects, For example, switching tube frequent breaking reduces the energy utilization efficiency and lifetime of the device, the improper design of the internal parameters of the commutation device will also bring a lot of problem such as convergence and stability of the system[1-3]; Furthermore, the power electronic devices as a non-linear load inject to grid, resulting in a large number of harmonics current, which brings a lot of security problems caused by heat stress. Traditional linear load statistics matching criteria in this environment has been challenged. Unstability caused by this power mismatch is also the key issue of smart micro-grid system, which consists of source converter output impedance and the input impedance of the load converter joint decision, in order to a more convenience study, there need establish an approximate mathematical model[2,4,5], taking into account the constant power characteristics of the Buck converter, there is a negative input impedance characteristics, according to a given Buck converter, change its load characteristics, and then separately to analyze the change in the impedance of the converter. Now study on DC/DC converter's negative impedance is mainly concentrated in the topology, internal parameters and control model, in this paper, change the output power to research Buck circuit input impedance characteristics.

\section{Design and Analysis of Voltage type Buck Converter}

\subsection{Analysis of Voltage Type Buck}

The Buck Chopper is the most widely used form of a circuit in the DC chopper circuit. Buck circuit is used to reducing the voltage of the DC power supply, it uses full-controlled device to control the DC source such of IGBT, MOSFET and so on, when closed, the DC power supply to the load, When turned off, the inductor has been charged still conduct through diode, supply power to load, so as to achieve the purpose of the step-down chopper. Having inferred to the following formulation:

$$
E=D U_{o}
$$

E-input DC voltage

D-duty

$U_{o}$ - output voltage

In order to stabilize and adjust the output voltage of the DC/DC converter, generally, use the voltage or current- control mode to adjust the duty cycle, as shown in Figures 1 and 2. Advantages of current mode control: faster transient response and improve the stability of the output voltage accuracy, and has current limiting function by itself, easy-to-achieve converter overcurrent protection, and thus easier for multiple power supplies in parallel achieve both streams. Voltage mode control: the advantages of detecting only one variable output voltage, and only one control loop, relatively simple to design and analysis; due to the large amplitude of the serrasoid waveform, having the strong anti-jamming capability. This article only analysis the Voltage type Buck converter.

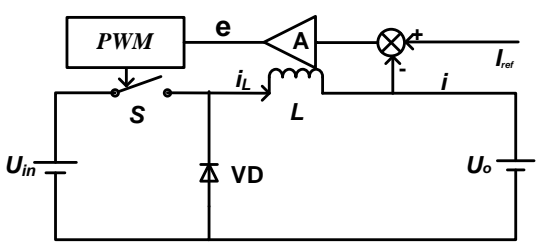

Figure 1. Current type Buck converter. 


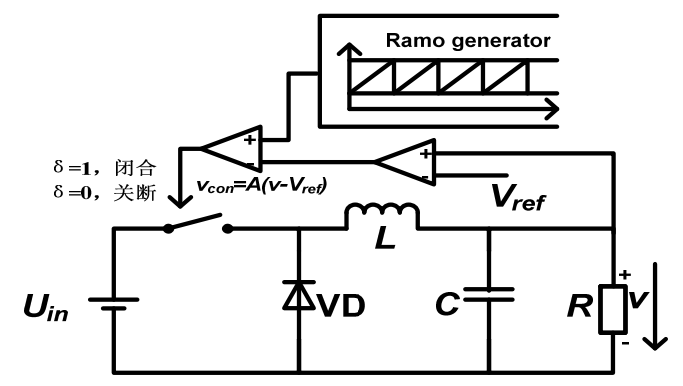

Figure 2 .Voltage type Buck converter.

For a more intuitive understanding of the negative impedance characteristics of the Buck converter, we assume that the BUCK circuit components are ideal, the power transfer efficiency of $100 \%$, the converter has been at the CCM model. The converters simulation can infer that inductance is smaller, the greater the overshoot, more stable; capacitance is smaller, smaller overshoot, the greater the ripple. Therefore there is need to calculate the appropriate filter capacitors, inductors which can meet the requirements of the simulation waveform.

For a more intuitive understanding of the negative impedance characteristics of the Buck converter, we assume that the BUCK circuit components are ideal, the power transfer efficiency of $100 \%$, the converter has been at the CCM model. The converters simulation can infer that inductance is smaller, the greater the overshoot, more stable; capacitance is smaller, smaller overshoot, the greater the ripple. Therefore there is need to calculate the appropriate filter capacitors, inductors which can meet the requirements of the simulation waveform.

\subsection{Small Signal Model}

The main course to analysis DC power converter is state space averaging method [6], given the coefficient matrix of the equation of state $A_{1}, b_{1}, A_{2}, b_{2}, C_{1}{ }^{T}, C_{2}{ }^{T}$ under two switching state, can infer the mathematical expressions that describe the steady-state and dynamic small signal characteristics, induce to the low-frequency equivalent mode, then through to the disturbance, linearization and other steps, can get low-frequency small-signal behavior equation:

$$
\begin{gathered}
\frac{d \hat{x}}{d t}=A \hat{x}+b \hat{v_{s}}+\left[\left(A_{1}-A_{2}\right) X+\left(b_{1}-b_{2}\right) V_{s}\right] \hat{d} \\
\hat{y}=C^{T} \hat{x}+\left(C_{1}^{T}-C_{2}^{T}\right) X \hat{d}
\end{gathered}
$$

By the formula (2) and (3) dynamic low-frequency response can be obtained by the Laplace transform of the small signal characteristics, such as the output of the input to the conduction ratio control transfer function. Deduced from the voltage on the conduction the transfer function $G_{v d}$ ratio control is as follows:

$$
\begin{aligned}
\left.\frac{\hat{y}(s)}{\hat{d}(s)}\right|_{\hat{v(s)=0}}= & C^{T}(s I-A)^{-1}\left[\left(A_{1}-A_{2}\right) X+\left(b_{1}-b_{2}\right) V_{s}\right] \\
& +\left(C_{1}^{T}-C_{2}^{T}\right) X
\end{aligned}
$$

Transfer function can be obtained from the above equation:

$$
G_{v d}=\frac{1}{S^{2}+\frac{S}{R C}+\frac{1}{L C}} \frac{1}{C} \frac{1}{L} V_{s}=\frac{1}{C L S^{2}+\frac{L}{R} S+1} \frac{V_{0}}{D}
$$

\section{Analysis and Simulation}

For deep understanding of the closed-loop input impedance characteristics of the converter, establish voltage-mode control of the synchronous rectifier BUCK converter model [7-9] and simulation, as shown in Figure 3; assuming the efficiency of the inverter is $100 \%$ :

$$
P_{0}=U_{i n} I_{\text {in }}
$$

In formula $U_{\text {in }}$ and $I_{\text {in }}$ is input voltage and input current. Small signal perturbations superimposed on the amount of the steady state in the above formula, get following formula:

$$
P_{0}+\hat{P}_{0}=\left(U_{i n}+\hat{u_{i n}}\right)\left(I_{i n}+\hat{i_{i n}}\right)
$$

Assuming the converter's output power is constant, that is to ignore the disturbance of the output power:

$$
P_{0}=U_{i n} I_{i n}+U_{i n} \hat{i_{i n}}+I_{i n} \hat{u_{i n}}+\hat{u_{i n}} \hat{i_{i n}}
$$

According to formula (6), then ignores the second order component:

$$
Z_{i c} \stackrel{\stackrel{\Delta}{=}}{\hat{i_{i n}}}=-\frac{U_{i n}^{2}}{P_{0}}
$$

The formula (9) explaining the reasons for a closed-loop input impedance appears the negative resistance characteristic. Absolute of input impedance depending on the size of the input voltage and output power, make input voltage constant, the converter's input current will be reduced when increasing the output power of the converter, and verify by simulation following.

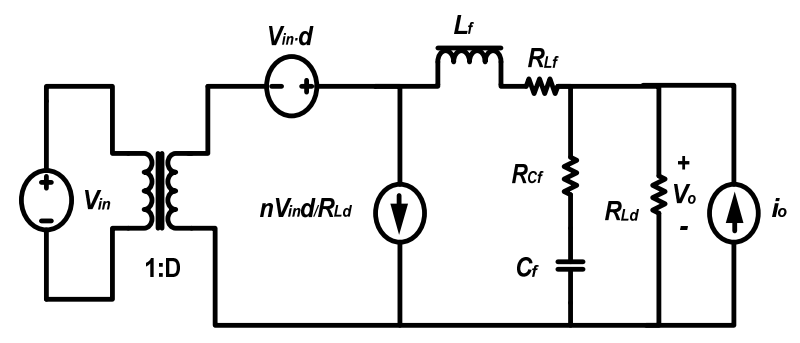

Figure 3. Buck converter small signal model. 


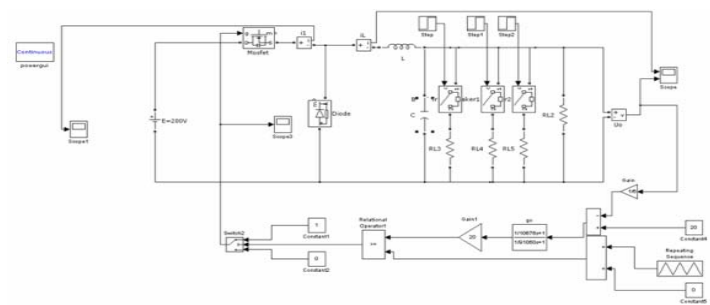

Figure 4. Simulation model.

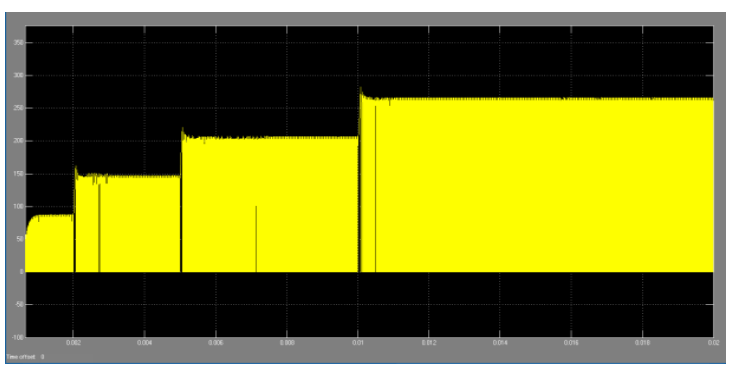

Figure 5. Current waveform.

In Buck converter simulation, set the voltage feedback loop control system, the converter input voltage $E=200$ $\mathrm{V}$, output voltage $U_{o}=120 \mathrm{~V}$, the initial resistive load is $1.5 \Omega$, due to it is assumed that the converter has been working in CCM state[10-12], according to inductance $L 、 C$ of formula, it can obtain the value of the $L, C$, and then multiplied by a certain margin coefficient, and finally set $L=6 \mathrm{e}^{-5} \mathrm{H}, C=5 \mathrm{e}^{-4} \mathrm{~F}$, make simulation time is 0.02 seconds, and paralle a plurality of resistive load in the load terminal, then trigger pulse at different times, the purpose of increasing the load is to observe the change of the input current, and the validation of the negative impedance characteristics. The simulation model is shown in Figure 4.

\section{Results of Simulation}

Since the input voltage is maintained at $200 \mathrm{~V}$, only observe the input current, the increase resistive load added in $0.002 \mathrm{~s}, 0.005 \mathrm{~s}, 0.01 \mathrm{~s}$, taking into account the efficiency of the inverter is $100 \%$, The obtained current waveform is shown in Figure 5.

Seen by the waveform diagram of the current in the load side of the power increase, the average of the input current increases, the input voltage to maintain the same circumstances, and seen by the Ohm's law, the input resistance of the converter decreases, showing negative impedance characteristics.

\section{Results of Simulation}

It get the same conclusion whether in theoretical way or simulation way, the voltage Buck converter exhibit negative impedance characteristics. In order to avoid the adverse effects of the negative impedance characteristics in engineering, They often put filter in the converter preceding, increasing the positive impedance to counteract the negative impedance converter produced, It lead us to use Buck converter input impedance characteristics to the next research, such as provides a good reference for study on DC bus stability.

\section{REFERENCES}

[1] H. Sira-Ramirez, "Slind Motions in Bilinear Swithed Networks," IEEE Transactions on Circuits Systems, Vol. 34, No. 8, 1987, pp. 919-933.

[2] X. Feng, et al.,"Individual Load Impedance Specification for a Stable DC Distributed Power System," IEEE APEC Record,1999.

[3] J. Sun and H. Grotstollen, "Symbolic Analysis of Switching Power Converters Based on a General Averaging Method," Power Electronics Specialists Conference, 27th Annual IEEE, Vol. 1, 23-27 June 1996, pp. 543-549

[4] B. Gao, G. K. Morison and K. P. Voltage, "Stability Evaluation Using Model Analysis," IEEE Transactions on PWS, Vol. 17, No. 4, 1992, pp. 1529-1536.

[5] D. Czarkowki, L. R. Pjara and M. K. Kazimierczuk, "Robust Stability of State-feedback Control of PWM DC-DC Push-pull Converter," IEEE Transactions on Industrial Electronics, Vol. 42, No. 1, 1995, pp.108-111.

\section{doi:10.1109/41.345854}

[6] F. L. Luo and H. Ye, "Positive Output Super-lift Converters," IEEE Transactions on Power Eletronics, Vol. 18, No. 1, 2003, pp. 105-113. doi:10.1109/TPEL.2002.807198

[7] F. Z. Peng, J. S. Lai and J. W. Mckeever, "A Multilevel Voltage Source Inverter with Separate DC Source for Static Var Generation," IEEE Transactions on Industry Applications, 1996

[8] T. C. Neugebauer, J. W. Phinney and D. J. Perreault, "Filters and Components with Inductance Cancellation," IEEE Transactions on Industry Applications, Vol. 40, No. 2, 2004, pp. 483-491. doi:10.1109/TIA.2004.824487

[9] Z. H. Zhao and W. M. Ma, "Coupling Model and Impedance Calculation of the Steel Ground Loops with Proximity Effect," IEEE Transactions on Electromagnetic Compatibility, Vol. 48, No. 3, 2006, pp. 522-529.

$$
\text { doi:10.1109/TEMC.2006.877780 }
$$

[10] E. Porter, S. Ang, K. Burgers, et al., "Miniaturizing Power Electronics using Multi-chip Module Technology," Proceedings of International Conference on Multichip Modules, 1997.

[11] S. Wang, F. C. Lee and W. G. Odendaal, "Characterization and Parasitic Extraction of EMI Filters Using ScatteringParameters," IEEE Transactions on Power Electronics, Vol. 20, No. 2, 2005, pp. 502-510.doi:10.1109/TPEL.2004.842949

[12] C. Batlle, E. Fossas and G. Olivar, "Stabilization of Periodic Orbits in Variable Structure Systems Application to DC/DC Power Converters," MAU-UPC-01/96,1996. 